\title{
Analysis of Serum Proteins Adsorbed to a Hemodialysis Membrane of Hollowfiber Type by Thermal Lens Microscopy
}

\author{
Hiroko KIMURA*1, Hiroshige KoJIMA*2, Masahiro MUKaIDA*3, Takehiko KITAMORI*4 \\ and Tsuguo SAWADA*4 \\ *1 Department of Forensic Medicine, Juntendo University School of Medicine, Tokyo 113-8421, Japan \\ *2 Analytical \& Computational Science Laboratory, Analytical Research Laboratory, \\ Asahi Chemical Industry Co., Ltd., Shizuoka, 416-8501, Japan \\ *3 Department of Forensic Medicine, National Defense Medical College, Saitama, 359-8513, Japan, \\ *4 Department of Applied Chemistry, Faculty of Engineering, The University of Tokyo, \\ Hongo, Bunkyo, Tokyo 113-8656, Japan
}

\begin{abstract}
To analyze serum proteins adsorbed to a hemodialysis membrane, immunostaining with colloidal gold and thermal-lens microscopy were employed. A total of 14 types of hemodialysis membranes were tested. The cross sections of the membranes were stained with fluorescent antibodies. Observations of these specimens using a laser microscope revealed that serum proteins, such as albumin and immuno globulins, tended to adsorb into the inner wall of these membranes. The degree of adsorption of serum proteins varied according to various conditions, such as what materials the membranes were made of or what proteins were adsorbed. For a better quantitative analysis of these proteins, the membranes were stained with immunogold and were observed by a thermal lens microscope. Colloidal gold coated with various antihuman serum proteins was used for the staining, and the quantity of colloidal gold was measured with a thermal-lens microscope. The quantity of colloidal gold, coated with anti-human sera antibody, gradiently decreased from the inner to the outer wall of the membrane. Probably, proteins with larger molecules were adsorbed to the inner parts, and those with smaller molecules were adsorbed to the outer parts of the membrane wall. High-resolution thermal-lens microscopy makes possible the sensitive detection of localized proteins adsorbed to a membrane without extracting it. Thus, the analysis of adsorbed proteins should serve to determine the adaptability of medical appliances to the human body and should also be helpful to a retrospective analysis of substances like drugs which are conjugated to the serum proteins.
\end{abstract}

Keywords Protein-analysis, hemodialysis membrane, immunostaining, colloidal gold, thermal-lens microscopy

Hemodialysis membranes are commonly used in medical practice for a variety of purposes. Depending on the materials of dialysis membranes, either adsorption of blood components to the membrane or elution of the materials into the blood occurs. As a result, the time for the dialysis is lengthened, causing a great pain to the patient. In clinical medicine, dialysis-amyroidosis is well known to be one of the most common complications; this occurs when small molecular proteins, such as $\beta_{2}$-microglobulin, are left unfiltered. ${ }^{1-4}$ One of the undesirable phenomena that lead to a failure of hemodialysis is blood coagulation in the tubes. ${ }^{5-9}$ This is caused mainly by the hemoagglutination activation protein. This protein makes white blood cells and platelets adhere to the surface of the membrane at the beginning of the coagulation process, thus impeding the successful outcome of dialysis. ${ }^{10}$ To prevent coagulation in the tubular membrane, a hemagglutination activator, which activates the coagulation process, should be shielded by other proteins or removed from the surface of the hemodialysis membrane. Although the adsorption of serum proteins to the hemodialysis membrane is empirically a well-known fact ${ }^{11}$, the type and/or amount of the adsorbed proteins is not clearly known. When analyzing the proteins adsorbed to the hemodialysis membrane, it is common to extract them from the membranes and to determine their concentrations by measuring their absorbance ${ }^{12,13}$ or radioactivity. ${ }^{11}$ However, the disadvantage of this method is that it requires a considerable amount of test samples, and the detection of local adherence of proteins to the membranes is difficult. Therefore, instead of this method, laser microscopy is commonly used to observe crosscut membranes stained with antibodies labeled with fluorescent substances. ${ }^{5,14}$ However, immunological staining with fluorescent labeling substances is not sufficiently stable for a long observation, and this technique still remains a semiquantitative analysis ${ }^{14,15}$, and is mainly used to detect the localization or distribution of substances. ${ }^{16,17}$ The analysis of serum proteins adsorbed to hemodialysis membranes is an important topic in the study of the adaptability of 


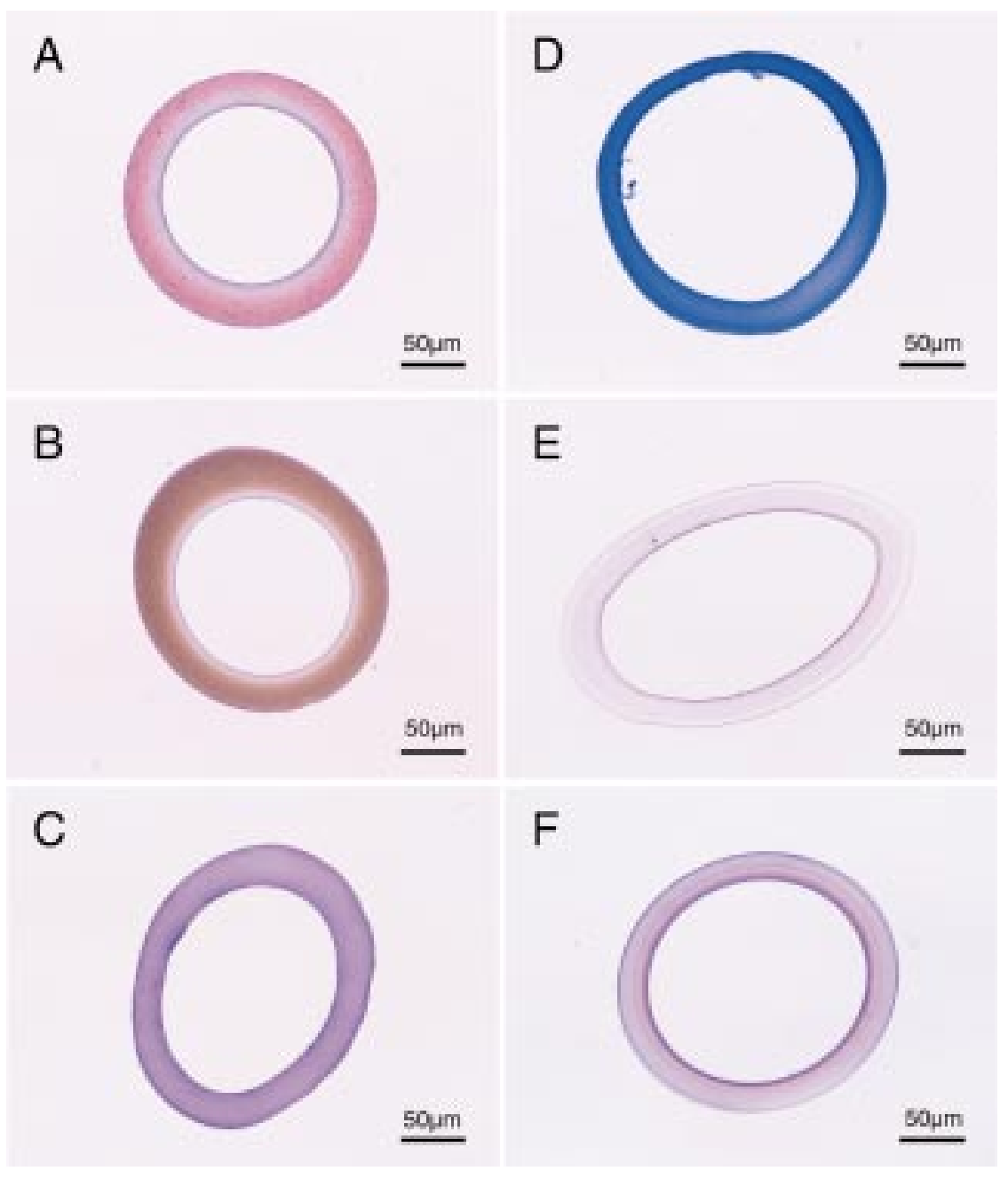

Fig. 1 Optical photomicrographs of various types of used membranes (crosscut) using CBB staining, A, APS; B, BS; C, AN; D, BK; E, EL; F, PAN.

medical appliances to the human body. In an attempt to obtain a more satisfactory quantitative analysis of proteins, we employed immunogold staining of the membranes, and then observed the stained membranes with a laser microscope and a thermal-lens microscope. ${ }^{18,19}$

\section{Materials and Methods}

\section{Dialysis membranes}

The following 14 types of hollow-fiber, hemodialysis membranes were used: polysulfone membrane (APS, BS, and PS), polyacrylonitrile membrane (PAN), acrylonitrile $(\mathrm{AN})$, polymethyl methacrylate membrane (BK and PMMA), cellulose membrane (BLF), ethylenevinyl alcohol membrane (KF, EL, and EVAL), polymer alloy membrane (FLX), cellulose membrane (AMSD), and polyamide membrane (PA). For each membrane, both used (for hemodialysis) and unused membranes were tested.

\section{Antibodies and labeled antibodies}

The following antibodies raised in rabbits were used: anti-human serum, anti-human albumin, anti-human immunoglobulin (anti-IgM+IgG+IgA), anti-human $\mathrm{IgG}$, anti- $\beta_{2}$ micro-globulin, anti-human transferrin, anti-human $\beta$-lipoprotein, and the anti-human IgM antibody raised in goat. Anti-goat IgG raised in rabbit serum was also used. Fluorescein isothiocyanate (FITC) or rhodamine labeled anti-rabbit IgG or antigoat IgG was used as fluorescent antibodies. The antibodies were all purchased from Cappel (Durham). Colloidal gold labeling of the antibodies was performed by a previously reported method. ${ }^{20}$

\section{Observation by laser microscopy and measurement by} thermal lens microscopy

To determine the type of proteins on the membranes, their crosscut sections on the slideglass were stained with antibodies labeled either with fluorescent substances or colloidal gold. The membrane specimens were fixed in a solution containing $4 \%$ paraformaldehyde and $2 \%$ glutaraldehyde and were frozen in an 

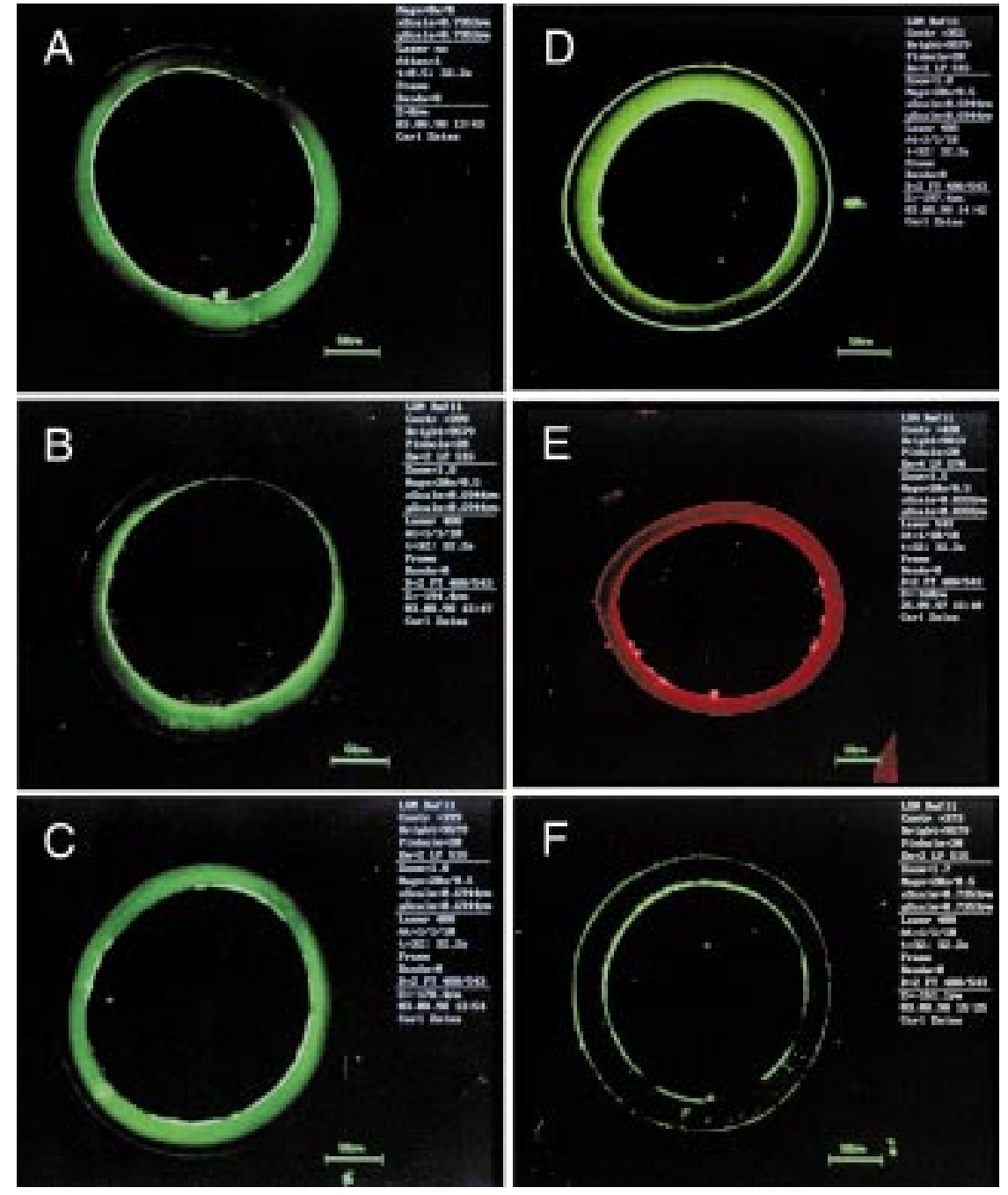

Fig. 2 Images of the used BK membrane using fluorescent immunostaining obtained with the laser microscope. A, anti-human serum; B, anti-albumin; C, anti$\operatorname{IgM}+\operatorname{IgG}+\operatorname{IgA}$; D, anti-IgG; E, anti-IgM; F, anti- $\beta_{2}$ microglobulin.

embedding medium for frozen tissue specimens (Miles, Naperville). These frozen membranes were cut into a series of $5 \mu \mathrm{m}$ thick sections. Some sections were used for protein staining with Coomassi Brilliant Blue (CBB, $0.01 \%$ CBB, $7 \%$ acetic acid and $10 \%$ methanol), while other sections were placed on gelatin-coated slide glasses for immunological staining. The latter sectioned specimens were placed in $10 \mathrm{mM}$ phosphate buffer ( $\mathrm{pH} 7.4$ ) containing $2 \%$ casein, $0.1 \%$ Triton $\mathrm{X}$ $100,10 \%$ normal rabbit serum (or normal goat serum) for $2 \mathrm{~h}$ at room temperature. Then, the sections were incubated with various kinds of antibodies labeled with colloidal gold. Only for the IgM detection, colloidal gold-labeled rabbit anti-goat $\operatorname{IgG}$ (second antibody) was employed after incubation with goat anti-human $\operatorname{IgM}$ (first antibody). For fluorescent immunostaining, the specimens were incubated with various kinds of antibodies, followed by incubation with FITC- or rhodamine-labeled second antibody for $2 \mathrm{~h}$ at room temperature. Specimens stained with a labeled antibody were air-dried and enclosed with Entellan (rapid mounting media for microscopy, containing xylene and alkylacrylate, E. Merck, Darmstadt, Germany) and were mounted under a coverglass for measurement. The specimens stained with $\mathrm{CBB}$ were then observed with an optical microscope (Olympus BH-2). The specimens stained with FITC- or rhodamin-labeled antibody were observed with a laser scanning microscope (Carl Zeiss Model 410, Oberkochen) using an excitation wavelength of $488 \mathrm{~nm}$ and a fluorescence wavelength of $515 \mathrm{~nm}$ (for FITC), and an excitation wavelength of $543 \mathrm{~nm}$ and a fluorescence wavelength of $570 \mathrm{~nm}$ (for rhodamine). The specimens stained with gold-labeling-antibodies were also observed with the laser scanning microscope in the reflection mode using both $488 \mathrm{~nm}$ and $514 \mathrm{~nm}$ of Ar laser. The same specimens stained with gold were then examined under a thermal-lens microscope. The thermal-lens microscopy equipment was illustrated in a previous article. ${ }^{21}$ It comprises a microscope with two laser- 


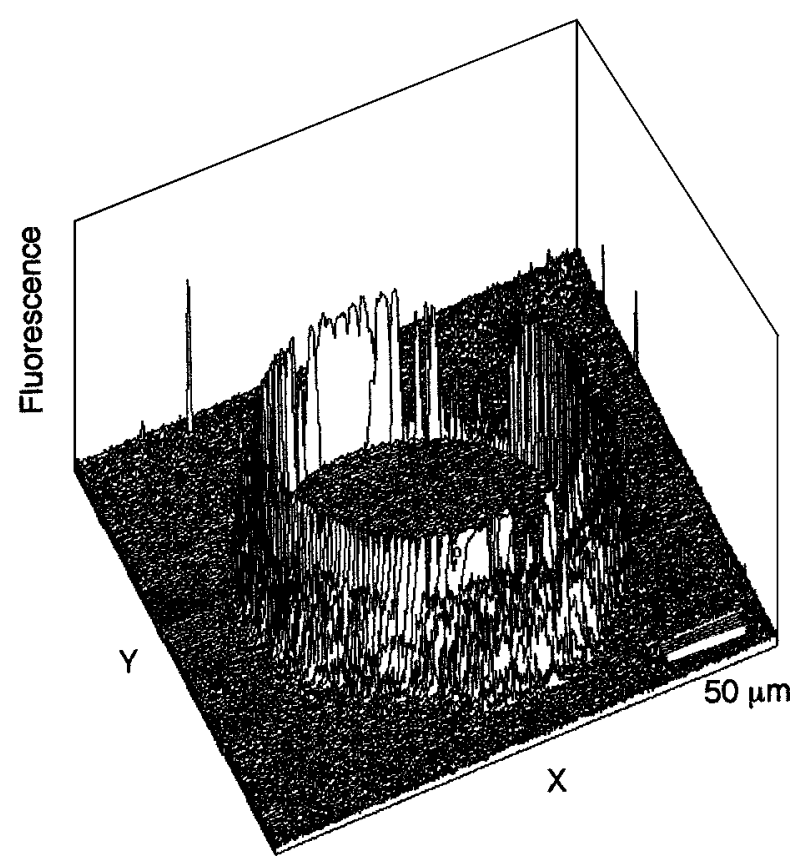

Fig. 3 Plot profile of the specimen shown in Fig. 2A. The data were obtained by an image-processing system equipped with a laser microscope.

oscillation apparatuses and other optical devices. In the present experiment, the excitation beam was the 514.5 $\mathrm{nm}$ emission line of an Ar-ion laser; the probe beam was the $633 \mathrm{~nm}$ line of a He-Ne laser.

\section{Calibration curves of serum proteins}

In order to make a standard curve of the protein concentration for a calibration graph, chips of polystyrene plates, to which human serum proteins were adsorbed, were prepared. Human serum proteins, which were diluted to various concentrations, were coated to the wells of a microtiter plate (Flat bottom, Coster, Cambridge), and the plate was left to stand overnight at $5^{\circ} \mathrm{C}$. After discarding the serum solution, the wells of the plate were washed with saline and the bottom plate of each well was cut to about $0.5 \mathrm{~cm}$ in diameter, 0.1 $\mathrm{cm}$ in thickness. Small chips of polystyrene plates, thus prepared, were placed on a slide glass for immunological staining and were stained with gold labeled antihuman serum antibody, by the same procedure used to stain membrane sections. The concentration of serum proteins adsorbed to the polystyrene chips was determined by measuring the absorbance at $280 \mathrm{~nm}$ of the serum specimens both before and after incubation to the microtiter plates.

\section{Results and Discussion}

Figures 1A, 1B, 1C, 1D, 1E, and 1F show typical optical photomicrographs of crosscut membranes of various materials stained with $\mathrm{CBB}$. Among these materials, BK membranes were stained with fluores- cent antibodies; their micrographs obtained by laser microscopy are shown in Figs. 2A, 2B, 2C, 2D, 2E, and $2 \mathrm{~F}$. Immunostaining of the cross sections revealed that various proteins were adsorbed between the inner wall and the edge of these membranes. The degree of adsorption of the proteins varied according to the different types of membranes. The fluorescent intensity corresponding to the amount of adhered proteins also varied in the same way as did the CBB density. The cross sections of clinically unused membranes, which were also stained with fluorescent antibodies as reference materials, on the other hand, exhibit no fluorescence at all (data are not shown). From these results, immunostaining with fluorescent antibodies was considered to be a specific staining. In fluorescent staining, the distribution of adsorbed proteins is clearly visualized, but the fluorescence intensity, which is shown in a plot profile (Fig. 3), being almost uniform, does not quantitatively reflect the local density of proteins. This is caused by a limited performance of the currently used image-processing system equipped with a laser microscope, and because of this the quantitative analysis is not very accurate or very perfect. Moreover, in fluorescent immunostaining the fluorescence intensity varies with every experiment. In immunogold staining, on the other hand, colloidal gold as a label has its absorption peak at $525 \mathrm{~nm}$, close to the $514.5 \mathrm{~nm}$ oscillation line of the Ar laser, and is stable under a strong laser beam. The stability of colloidal gold staining in an observation with a microscope is suitable particularly for quantitative analysis. We have already reported that thermal-lens microscopy is a better analytical method than laser microscopy to examine immunogoldstained specimens. ${ }^{19}$ Therefore, this thermal-lens microscopy was adopted to analyze serum proteins adsorbed to hemodialysis membranes.

Among various membrane materials, a polymethylmetacrylate membrane (BK) was used as an experimental material. Crosscut BK membranes were incubated with various kinds of antibodies labeled with colloidal gold. The quantity of the colloidal gold was measured by thermal lens microscopy. Because the hollow tube of the membrane has about $20 \mu \mathrm{m}$ thickness, the coaxial beams, i.e. the excitation and probe beams, scanned the gold adsorbed to the membrane for $150 \mu \mathrm{m}$, from the outer wall to the inner wall of the membrane linearly.

To determine what kinds of the serum proteins were adsorbed to the membrane, serial sections of the membrane were stained with 8 different gold-labeled antibodies against human serum components (anti-human serum, anti-albumin, anti-IgA+IgG+IgM, anti-IgG, anti-IgM, anti- $\beta_{2}$ micro-globulin antibodies). Figures $4 \mathrm{~A}, 4 \mathrm{~B}, 4 \mathrm{C}, 4 \mathrm{D}, 4 \mathrm{E}$, and $4 \mathrm{~F}$ show micrographs of membranes stained with various anti-human serum components labeled with colloidal gold. The images were obtained with the laser microscope in the reflection mode using the $488 \mathrm{~nm}$ and $514 \mathrm{~nm}$ lines of an Arlaser beam. These are digitized images by a computer- 

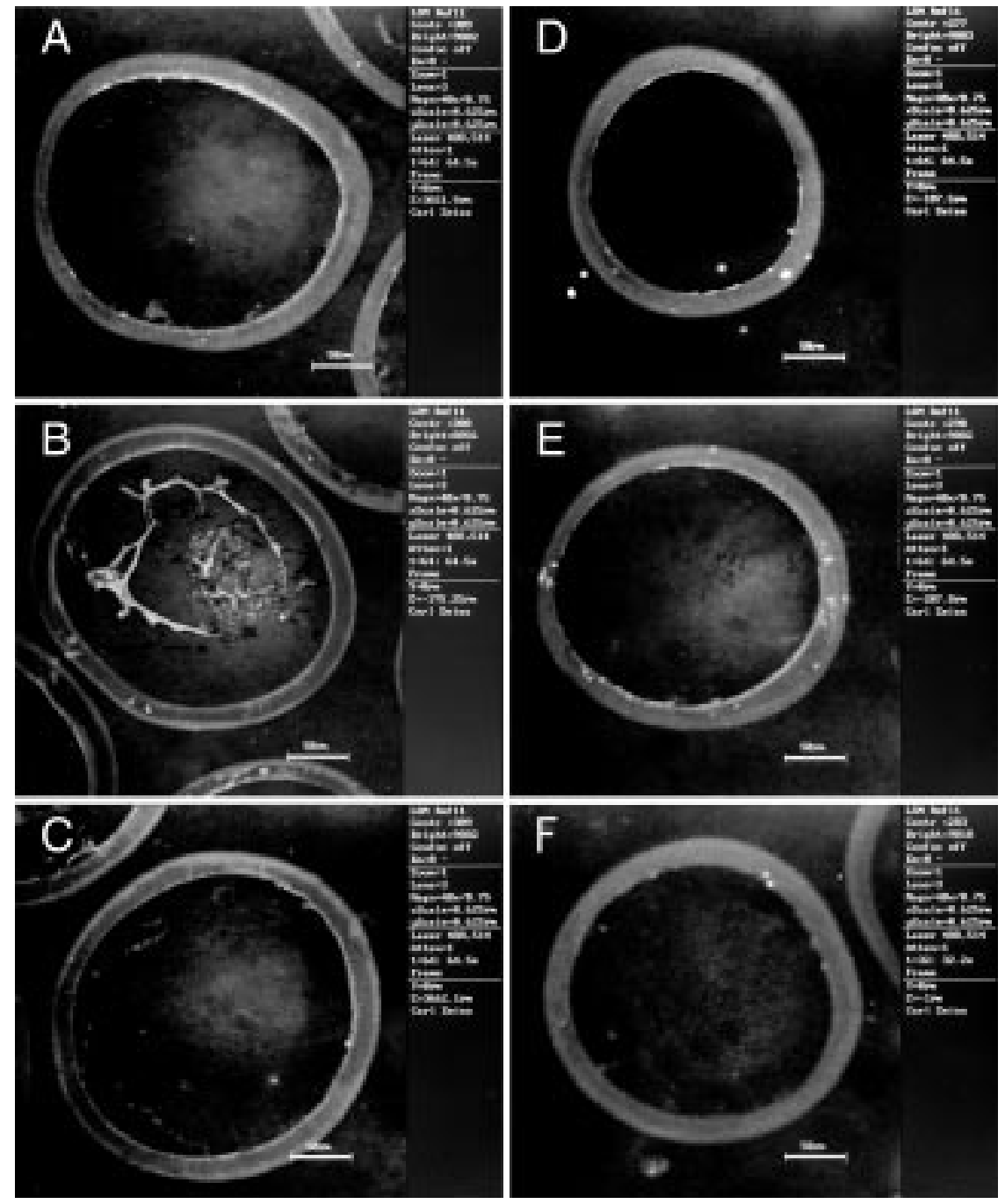

Fig. 4 Images of the BK membrane using immunogold staining obtained with a laser microscope. A, anti-human serum; B, anti-albumin; C, anti-IgM+IgG+IgA; D, anti-IgG; E, anti-IgM; F, anti- $\beta_{2}$ micro-globulin. The white parts show where proteins are adsorbed to the membrane.

ized image-processing system. In the micrographs the immunoreactivity is revealed by the brightness of the gold reflection, the white (i.e. bright) part being the place where gold (i.e. protein) adsorption is concentrated. A clinically unused membrane, to which serum proteins were not adsorbed, exhibits no effective signal by these gold-labeled antibodies (the photograph is not shown), while a positive reaction was observed on the sections of a used hemodialysis membrane. From these results, it is clear that gold adhesion to the used membranes was caused by a specific immune reaction, and that these different serum components are detected on the sections of the membrane. To determine the part of the membrane where these serum proteins were adsorbed, and also to quantitate these proteins, the same specimens stained with gold were measured by thermal-lens microscopy. Figure 5 shows scanning profiles of the gold quantity, determined with the thermallens microscope, which adsorbed to the cross-sectional membrane. The laser beams scanned the surface of the specimens on a moving stage from the outer wall to the inner wall of the membrane at 3 different parts. As for the membrane which was stained with anti-human sera, the whole section was scanned (Fig. 6). These results show that the quantity of colloidal gold tends to decrease gradually from the inner wall to the outer wall of the membrane. As shown in Fig. 5, relatively large molecular proteins, such as IgM and macroglobulin, adsorb to the region nearer to the inner wall of the membrane, while smaller molecular proteins, such as $\beta_{2}$ microglobulin and transferrin, pass through the membrane inner wall and adsorb to whole parts. Although the degree of adsorption of these proteins depends upon their shape and size, concentration, affinity to the surface of membranes, and many other conditions, proteins with larger molecules tend to adsorb to the inner parts and those with smaller molecules to the outer parts. Among the tested samples, the specimen 

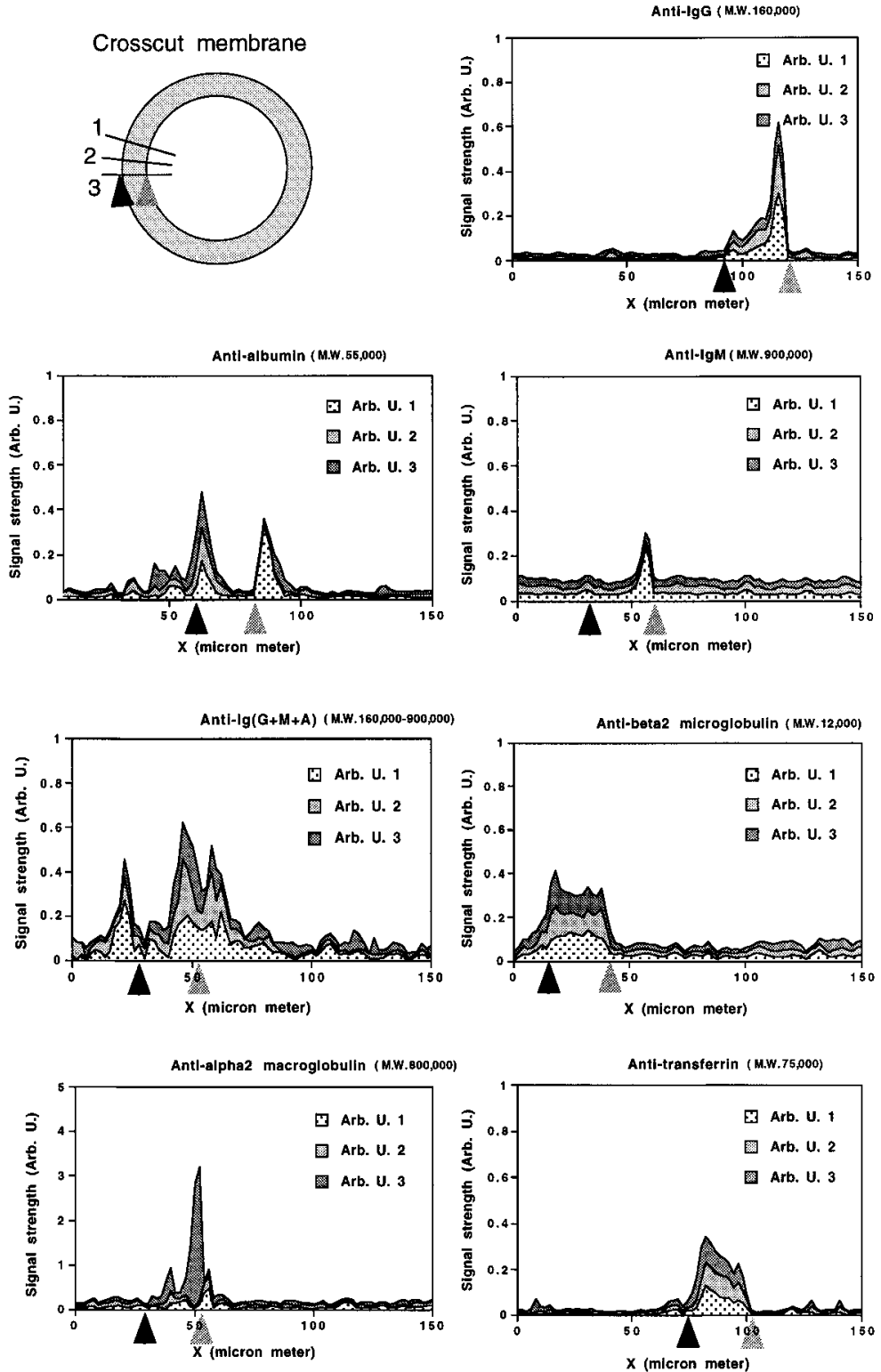

Fig. 5 Scanning profiles of a BK membrane stained with 7 different gold-labeled antibodies against human serum components. The quantity of gold adhered to the crosscut membrane was measured by thermal lens microscopy. The measured part is illustrated at the top left.

stained with anti-albumin-gold adsorbed to the inner as well as on the outer wall of the membrane, and the part in-between was almost unstained. This is probably because the pores of the membrane were larger there than at the inner and outer parts, and albumin, having a relatively small molecular weight (50000 - 60000), can well pass through the membrane. The fact that it remained on the inner wall probably indicates either its aggregation or conjugation with other proteins. Heterogeneity in protein adsorption to the membrane, even in one section, is probably due to the inhomogeneity of the synthesized membrane.

Figure 7 shows a calibration curve for serum protein concentrations adhered to the membrane wall. Four different concentrations of human serum proteins were adsorbed to polystyrene chips; these chips were incubated with antibody-labeled colloidal-gold. Colloidal gold was quantitated by thermal-lens microscopy, as in the case of membranes. The quantity of human serum proteins adsorbed to the membrane was calculated to be 13 ng per cross-section of the membrane. The protein amount calculated by this method corresponded almost to the amount measured by other methods. ${ }^{22}$ The amount of the other serum proteins, which are adsorbed to membranes, can be quantified by the same procedures.

ABO blood types could be determined from the erythrocytes that adhered to the hollow membrane. Thus, the analysis of serum proteins in the membrane is also helpful for a retrospective analysis of substances which 


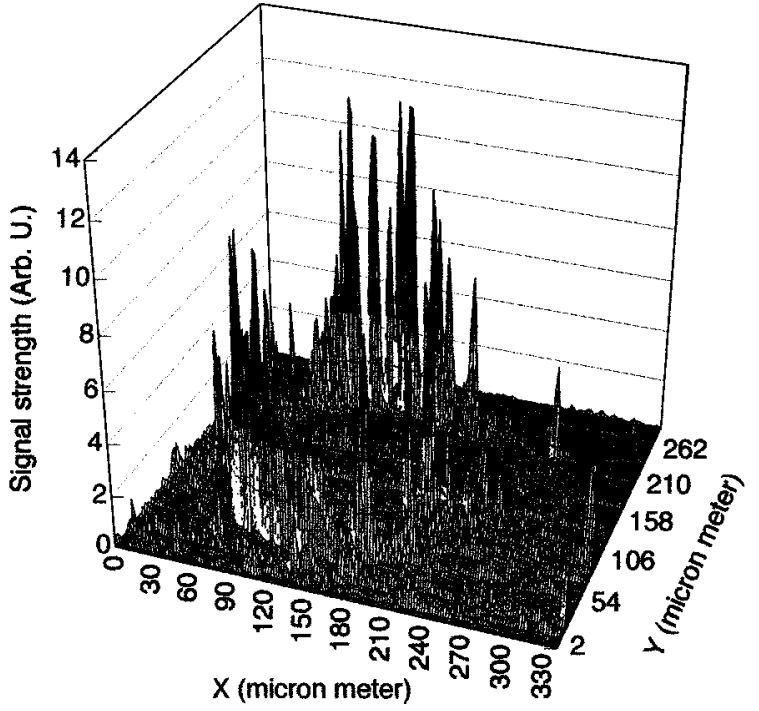

Fig. 6 3D scanning profile of a membrane stained with goldlabeled anti-human serum.

conjugated to the serum proteins.

Our thermal-lens microscope employing immunogold staining is a powerful device to analyze, both qualitatively and quantitatively, the proteins adsorbed to dialysis membranes. Since the size of membranes is almost $200 \mu \mathrm{m}$ in diameter, and the excitation laser beam can irradiate a target with a spot size of $1.5-2 \mu \mathrm{m}$, we could detect and measure the limited local concentration of serum proteins without extraction. The microanalysis of the serum proteins adsorbed to the membrane will surely contribute to the advancement of the biomaterial study.

\section{References}

1. J. M. Campistol, R. Molina, D. B. Bernard, R. Rodriguez, E. Mirapeix, J. M. Munoz-Gomez and L. Revert, Am. J. Kidney Dis., 22, 691 (1993).

2. T. Risler, N. Braun, K. D. Hanel, U. Kuhlmann, D. Skroch and G. A. Muller, Int. J. Artif. Organs, 17, 581 (1994).

3. A. Sivri, R. Celiker, C. Sungur and Y. G. Kutsal, Scand. J. Rheum., 23, 287 (1994).

4. T. Drueke, M. Touam and J. Zingraff, Adv. Renal Replac. Ther., 2, 24 (1995).

5. C. Barozzi, G. Cairo, R. Fumero, S. Scuri, M. C. Tanzi and P. Albonico, Life Sup. Systems., 3 (Suppl. 1), 490 (1985).

6. R. L. Mehta, ASAIO J., 40, 931 (1994).

7. N. J. Ofsthun and J. K. Leypoldt, Artif. Organs, 19, 1143 (1995).

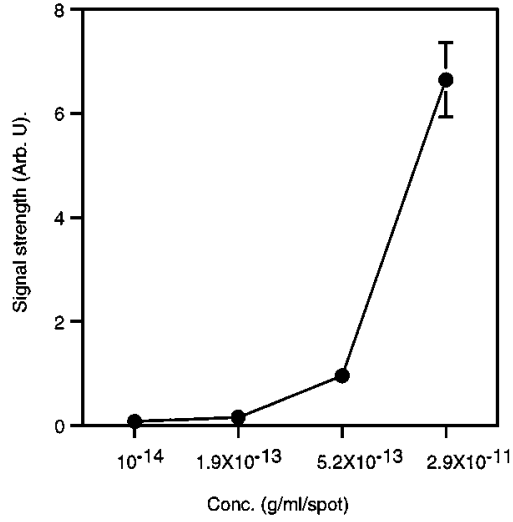

Fig. 7 Calibration curve for human serum protein concentrations determined by thermal-lens microscopy. The excitation laser beam irradiated a target with a spot size of $1.5-2 \mu \mathrm{m}$ in diameter. The thickness of proteins adsorbed to the chip was about $50 \mathrm{~nm}$.

8. J. Bohler, P. Schollmeyer, B. Dressel, G. Dobos and W. H. Horl, J. Am. Soc. Nephrol., 7, 234 (1996).

9. Y. Ishii, S. Yano, H. Kanai, A. Maezawa, A. Tsuchida, R. Wakamatsu and T. Naruse, Nephron., 73, 407 (1996).

10. C. Barozzi, G. Cairo, R. Fumero, S. Scuri, M. C. Tanzi and P. Albonico, Life Sup. Systems, 3 (Suppl. 1), 490 (1985).

11. W. R. Clark, W. L. Macias, B. A. Molitoris and N. H. Wang, Kidney Int., 48, 481 (1995).

12. U. Nensel, A. Rockel, T. Hillenbrand and J. Bartel, Blood Purif., 12, 128 (1994).

13. G. A. M. Francoise, J. Mallet, A. Tridon and P. Deteix, $J$. Biomater. Sci. Polymer Ed., 2, 263 (1991).

14. A. Fujimori, H. Naito and T. Miyazaki, Artif. Organs, 22 1014 (1998).

15. K. S. Rastogi, R. L. Cooper, Z. Q. Shi and M. Vranic, Endocrine, 7, 367 (1997).

16. D. S. Albers, S. W. Weiss, M. J. Iadaroa and D. G. Standaert, Neuroscience, 89, 209 (1999).

17. P. S. Leung, T. P. Wong, P. Y. Wong and H. C. Chan, Cell. Biol. Int., 22, 193 (1998).

18. H. Kimura and M. Mukaida, Jpn. J. Legal Med., 50, 241 (1996).

19. H. Kimura, M. Mukaida, T. Kitamori and T. Sawada, Anal. Sci., 13, 729 (1997).

20. H. Kimura, S. Matsuzawa, C-Y. Tu, T. Kitamori and T. Sawada, Anal. Chem., 68, 3063 (1996).

21. M. Harada, K. Iwamoto, T. Kitamori and T. Sawada, Anal. Chem., 65, 2938 (1993).

22. H. Y. K. Chuang, W. F. King and R. G. Mason, J. Lab. Clin. Med., 92, 483 (1982).

(Received July 14, 1999)

(Accepted September 6, 1999) 